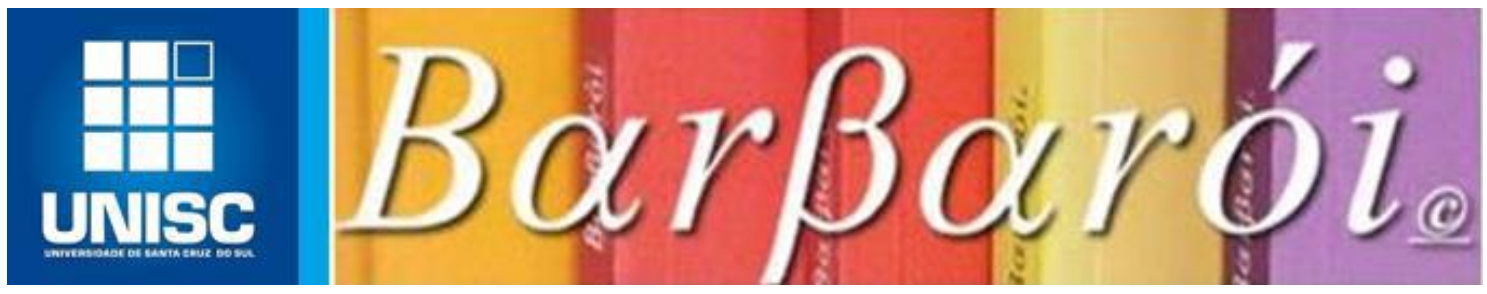

\title{
QUANDO A PARTICIPAÇÃO POPULAR É INÓCUA: O GREENWASHING DO CARVÃO NA REGIÃO METROPOLITANA DE PORTO ALEGRE/RS
}

\author{
DOI: http://dx.doi.org/10.17058/barbaroi.v0i0.14600
}

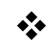 \\ Markus Erwin Brose \\ Universidade de Santa Cruz do Sul - UNISC-Brasil
}

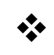

\begin{abstract}
Resumo
O presente ensaio propõe análise crítica dos mecanismos participativos utilizados no processo de licenciamento do Projeto Mina Guaíba, na Região Metropolitana de Porto Alegre. Cobrindo 4.380 hectares trata-se da maior lavra de carvão mineral a céu aberto no país, visando abastecer Polo Carboquímico composto por termelétrica, usina de gaseificação e indústrias de fertilizantes a serem construídos por estatais chinesas. Apresenta a hipótese que a decisão pela construção do polo foi incentivada pelo governo da China que, desde a crise de poluição atmosférica pelas termelétricas a carvão, em 2013, financia a exportação da capacidade ociosa de planejamento e construção de instalações industriais. De modo receptivo, o governo gaúcho criou, em 2017, o programa PROCARVÃO-RS buscando atrair expertise e capital chinês. Com base em referencial metodológico estabelecido por pesquisa pelo IPEA, e utilizando a Escada de Arnstein, conclui que as audiências públicas realizadas na região metropolitana são inócuas quanto aos objetivos da Política Gaúcha sobre Mudanças Climáticas, na medida em que não alteram escopo ou alcance da implantação da lavra, se restringindo a adicionar eventuais medidas compensatórias.
\end{abstract}

Palavras-chave: Carvão mineral. Poluição atmosférica. Mina Guaíba.

\section{Introdução}

No processo de redemocratização da federação brasileira, a cultura política gaúcha mereceu destaque pelas inovações introduzidas ao longo das primeiras duas décadas. Como reação à centralização de recursos e dos processos decisórios durante o Regime Militar, a sociedade gaúcha introduziu mecanismos diversos de participação, especialmente nos anos 1990/2000. Conforme Fonseca (2019) "testando inovações", buscando radicalizar a democracia, descentralizando a aplicação dos recursos públicos para o interior do estado.

Com base na experiência de fóruns microrregionais de planejamento em regiões como Ijuí e Santa Maria, a partir de 1989 foram formados os Conselhos Regionais de 
Desenvolvimento (Coredes), que contemplaram todo o território do estado e dialogavam com o recém-criado Conselho Estadual de Desenvolvimento sobre prioridades para o orçamento estadual (TIRELLI; AGOSTINI, 2015). Em paralelo, eram testadas assembleias populares nos bairros da capital para discutir prioridades do investimento público, enquanto na cidade de Pelotas eram realizadas assembleias distritais do orçamento municipal. A partir de 1993/94 foi consolidado o orçamento participativo na capital gaúcha, que ao longo de quatro administrações do campo democrático-popular tornou-se referência nacional e internacional (AVRITZER; NAVARRO, 2003).

Nos anos 2000, a busca pela legitimação do ciclo orçamentário estadual colocou em campos opostos os Coredes, o Executivo que priorizava o orçamento participativo como consulta popular e as prerrogativas da Assembleia Legislativa (TAVARES, 2006). Em iniciativa sem precedentes, os deputados levaram o debate orçamentário ao interior do estado através da Caravana da Democracia, realizando audiências públicas nos polos regionais (FARIA, 2006). A disputa foi levada ao Supremo Tribunal Federal, que teve que deliberar quanto à concorrência entre esses formatos de radicalização da democracia, debate até então inédito na federação brasileira.

Este contexto deu origem, em 2001, à experiência do Fórum Social Mundial. Arena de debates e propostas inaugurada em Porto Alegre como contraponto ao mainstream econômico global congregado no fórum da cidade de Davos, resort turístico na Suíça. Em ritmo anual, o Fórum congregou lideranças, pensadores e militantes do campo democrático-popular conferindo destaque aos conflitos da sociedade gaúcha quanto aos rumos do desenvolvimento territorial (SANTOS, 2002; STRECK, 2004).

As três décadas de inovação e conquistas para qualificação da democracia gaúcha constituem referência para a presente reflexão, que visa analisar os mecanismos de participação popular no processo em curso de licenciamento do maior Polo Carboquímico do continente a ser localizado no município de Charqueadas, na Região Metropolitana de Porto Alegre (RMPA). O argumento aqui desenvolvido está baseado em dados coletados mediante visitas técnicas e entrevistas realizadas, entre 2017/18, nos municípios de Charqueadas, Arroio dos Ratos e São Jerônimo, bem como revisão bibliográfica, no âmbito do projeto de pesquisa: Planejando paisagens: adaptação à mudança climática, fomentado pela Universidade de Santa Cruz do Sul (UNISC).

Além desta Introdução, o ensaio está dividido em quatro seções. A primeira seção discute o referencial teórico para análise de mecanismos participativos. A próxima seção apresenta síntese do Projeto Mina Guaíba, resumindo as audiências públicas realizadas no Barbarói, Santa Cruz do Sul, Edição Especial n.54, p.<173-19o>, jul./dez. 2019 
âmbito do processo de licenciamento. Na terceira seção é realizada discussão quanto aos dados apresentados, e a quarta e última seção apresenta primeiras conclusões.

\section{A qualidade da participação}

A bibliografia especializada não registra consenso quanto à definição do escopo de uma audiência pública. Diferentes mecanismos legais abrigam fenômenos distintos entre si. Como regra geral, podem ser diferenciadas audiências públicas obrigatórias, espaços de comunicação e consulta congregando distintos atores sociais por determinação legal, e audiências voluntárias, que podem adotar procedimentos metodológicos variados de acordo com os objetivos do empreendedor.

Segundo Fonseca; Alencar (2012) quatro características unificam o mecanismo das audiências públicas: elas são abertas, não sendo cerceada a participação de nenhum ator social; são pontuais, não mantém permanência; tem caráter presencial, ao contrário das consultas públicas que podem ser realizadas virtualmente, e principalmente, possuem caráter consultivo, não possuindo poder deliberativo. O organizador detém poder discricionário para considerar, ou não, as informações recebidas na audiência pública no processo decisório.

O Instituto de Pesquisa Econômica Aplicada (IPEA) institucionalizou, em 2010, o Programa de Pesquisa sobre Democracia e Participação. Iniciando com a definição de parâmetros de avaliação da efetividade de mecanismos participativos mediante coletânea com pesquisadores e técnicos do governo federal (PIRES, 2011), promovendo estudos diversos ao longo da década (SILVA, 2018). Neste período foram realizadas pesquisas específicas sobre mecanismos participativos como conselhos, conferencias e ouvidorias.

Ressaltamos a componente Diagnóstico e Avaliação das Audiências Públicas Realizadas no Âmbito do Governo Federal com argumento por Fonseca; Alencar (2012, p. 10) no relatório preliminar, "estudos e as análises ainda são reduzidos; de um modo geral, as audiências públicas são eventos pontuais, ou seja, ocorrem em momentos específicos do ciclo de políticas públicas, não há um conhecimento sistematizado”. As conclusões, visando aperfeiçoar audiências públicas, foram apresentadas em forma de guia para a Secretaria Geral da Presidência da República (FONSECA, 2013). Entre as conclusões, chama atenção para o contexto das audiências públicas, influenciados não apenas pelos atores sociais presentes, mas, igualmente pelo debate que ocorre na sociedade regional.

Experiências de participação em nível local sofrem grande influência do contexto social e político de maior escala, o que muitas vezes tem impacto sobre sua efetividade e perenidade. Sem um vínculo direto com processos políticos mais amplos, as deliberações Barbarói, Santa Cruz do Sul, Edição Especial n.54, p.<173-19o>,jul./dez. 2019 
oriundas de fóruns participativos e deliberativos podem não se traduzir em ações concretas, pois instâncias locais muitas vezes carecem de prerrogativas e capacidades para incidir sobre políticas públicas em diversos níveis de governo (Fonseca, 2019, p. 7).

Esta a razão pela qual as audiências públicas figuram entre os mecanismos participativos de menor efetividade, na medida em não há institucionalização das decisões, ou seja, não ocorre vinculação direta e obrigatória entre deliberações da assembleia e o orçamento público, ou o investimento privado.

\begin{abstract}
Por grau de institucionalização, entende-se a incorporação dos mecanismos no âmbito do Estado, por meio de um vínculo direto entre os resultados da instância participativa e o processo decisório em torno de políticas públicas [...] A institucionalização tem como objetivo garantir certa perenidade aos mecanismos, assim como formalizar sua integração ao processo de policy making e ao ciclo de gestão de políticas públicas. (FONSECA, 2019, p. 8).
\end{abstract}

Com base em estudos de caso, os pesquisadores do IPEA elaboraram uma tipologia que classificou a organização, ou seja, o processo das audiências públicas em cinco classes, de acordo como objeto, natureza, abrangência, timing de realização e tipo de participante. O projeto também resultou em referencial metodológico para avaliação da efetividade da audiência pública. Assim, no relatório final Fonseca (2013a) propõe avaliar audiências públicas de acordo com quatro dimensões: 1. Impacto na tomada de decisão e em compromissos políticos. 2. Mediação: diminuição de conflitos e aumento da cooperação. 3 . Construção de capacidades (capacity building). 4. Divulgação das ações pelo empreendedor (abertura por parte do governo e envolvimento da sociedade).

Especialmente quanto ao Item 3-Construção de capacidades, o relatório final destaca que nos estudos de caso analisados, entre 2011/12, houve pouca efetividade.

As audiências públicas assumiram, principalmente, um papel de informar, tirar dúvidas e colher contribuições. Nesse sentido, pode-se considerar que as audiências assumiram, em parte, uma característica de pergunta/resposta que não politizou nem promoveu a prática discursiva entre os envolvidos. (FONSECA, 2013a, p. 67).

O relatório final destaca, ainda, que em casos de megaprojetos, o mecanismo da audiência pública, mesmo sendo uma ferramenta participativa, apresenta limitações metodológicas, por exemplo, concede poucos minutos para cada fala dos presentes. Os analistas do IPEA recomendam passar de um evento para a construção de um processo participativo no qual a audiência pública deve ser complementada com outros mecanismos, tais como oficinas preparatórias, assembleias, campanhas educativas ou conselho popular de monitoria. Destacamos como conclusão central desta componente de pesquisa a constatação quanto ao poder decisório debatido por ocasião da audiência pública da usina de Belo Monte. 
Como foi esclarecido pelo representante da Eletrobrás na audiência de Vitória do Xingu, a decisão de construir Belo Monte ocorreu em momento muito anterior à audiência, há mais de trinta anos. Tal decisão foi tomada pelo governo e pelo setor elétrico, sendo expressa em diversos planos energéticos nacionais desde o PNEE 1987-2010. Assim, para que a população possa interferir nesta decisão, deve haver uma democratização na elaboração destes planos, que atualmente apresentam um modelo técnico e fechado para a participação social. Isto desmistificaria a ideia de que o instituto ambiental, por ser responsável pela licença, é o grande responsável pela aprovação ou recusa de projetos de infraestrutura. (FONSECA, 2013a, p. 120).

A decisão pela construção ocorreu "há mais de trinta anos", e os analistas do IPEA chegaram à conclusão que estruturalmente uma audiência pública constitui espaço de ouvidoria, de registro de reclamações, mas não constitui um fórum deliberativo. "É importante atentar que diversas políticas públicas demandam outros instrumentos participativos em vez de audiências públicas” (FONSECA, 2013a, p. 124). As decisões quanto a projetos do setor elétrico, por exemplo uma termelétrica a carvão, são tomadas anos antes da obra por agentes econômicos que não estão presentes na audiência pública, enviam seus representantes locais para cumprir com o ritual formal do registro na fotografia e na lista de presença.

Conclusão similar fora apresentada pela urbanista Sherry Arnstein, com base em sua experiência com políticas de habitação social nos EUA para população afro-descendente. Arnstein (1969) propôs uma escala para aferir o grau de efetividade da repartição de poder em mecanismos de participação, a Escada de Arnstein. A autora estabelece uma tipologia com oito níveis de qualidade da participação, desde o degrau da manipulação, no qual mecanismos participativos são utilizados para cooptar e apaziguar demandas populares, até a auto-gestão, degrau no qual a população envolvida toma decisões através de mecanismos participativos e dispõe dos recursos necessários para sua implementação.

Encerrando a discussão do referencial metodológico, ressaltamos que uma das formas de manipulação da opinião pública constitui a desinformação planejada, a divulgação de promessas que não são cumpridas pelo produto ou serviço ofertado. $\mathrm{O}$ caso de atributos ambientais de um produto ou serviço que não podem ser constatados de forma objetiva constitui o Greenwashing, ou "Mentira Verde" conforme tradução pelo Instituto de Defesa do Consumidor (IDEC, 2019). Produtos que se dizem ambientalmente corretos, mas não especificam os fatos e dados científicos em que são baseados. 


\section{Estudo de caso: o licenciamento do Projeto Mina Guaíba}

\section{O Projeto Mina Guaíba}

Apresentada em evento público pelo governador pouco antes do final de mandato, em novembro de 2018, a Política Estadual de Fomento à Mineração estabelece o macro-objetivo: “Apoiar o planejamento e a gestão sustentável dos recursos minerais, promovendo a competitividade do setor e a geração de valor, riqueza e emprego para o desenvolvimento socioeconômico do RS” (RS, 2018). Contrário ao discurso liberal que tem se tornado usual durante as campanhas eleitorais, o Executivo gaúcho assume a responsabilidade em assegurar a competitividade da cadeia produtiva da mineração no estado. O plano estratégico 2019/22 da nova Secretaria de Meio Ambiente e Infraestrutura (RS, 2019), prioriza o Programa de Incentivo ao Uso Sustentável e Diversificado do Carvão Mineral (PROCARVÃO-RS).

Estes documentos oficiais, porém, não registram o maior e mais impactante investimento em fase de licenciamento no estado, na divisa dos municípios de Eldorado do Sul e Charqueadas na RMPA. O Projeto Mina Guaíba de propriedade da empresa COPELMI Mineração Ltda., com sede na cidade de Porto Alegre, anunciado como parceria com a empresa Air Products and Chemicals, com sede na cidade de Allentown/Pennsylvania, e a empresa Zhejiang Provincial Energy Group Company, com sede em Hanghzou/China. O projeto está situado a $17 \mathrm{~km}$ em linha reta do centro da capital gaúcha, no entorno da Área de Proteção Ambiental (APA) Delta do Jacuí.

O Estudo de Impacto Ambiental (EIA) com sete volumes, sintetizados no Relatório de Impacto Ambiental (RIMA), foi produzido, em 2018, pela empresa ABG Engenharia e Meio Ambiente Ltda., com sede na cidade de Porto Alegre, em parceria com a empresa Tetra Tech Engenharia e Consultoria Ltda., com escritório na cidade de São Paulo, subsidiária da empresa Tetra Tech Consulting, com sede na cidade de Pasadena/Califórnia. O estudo (COPELMI; ABG; TETRA TECH, 2018) prevê a criação inicial de 335 empregos diretos na mina. Com base na projeção pelo empreendedor de investimento inicial de $\mathrm{R} \$ 600$ milhões, significa um custo estimado em $\mathrm{R}$ \$ 1,8 milhão/vaga, prevendo chegar a 1.154 empregos diretos, até 2042.

O projeto engloba 4.380 hectares localizados na RMPA, na bacia hidrográfica do rio Jacuí que abastece parte significativa da economia gaúcha. A mina irá desalojar mais de 200 famílias, além de um assentamento de reforma agrária com 72 famílias. Estão previstos a extração de 166 milhões de toneladas de carvão bruto ao longo de 23 anos de operação. Tendo em vista a baixa qualidade do carvão gaúcho, com mais de $60 \%$ de material estéril que Barbarói, Santa Cruz do Sul, Edição Especial n.54, p.<173-19o>, jul./dez. 2019 
inviabiliza o transporte, a mina torna-se viável somente mediante a instalação de empreendimentos de processamento do carvão à boca da mina, denominado Polo Carboquímico.

\section{O Polo Carboquímico e o 'carvão sustentável'}

O Projeto Mina Guaíba representa, portanto, primeiro passo de um complexo carboquímico com promessa, segundo o empreendedor, de atrair recursos da ordem de USD 4,4 bilhões de investimento externo. Congregando projetos para uma planta com capacidade para produzir dois milhões de metros cúbicos diários de gás sintético, uma termoelétrica a carvão mineral, além de indústrias de fertilizantes, nafta e plásticos, que não estão sendo licenciados. Em entrevista, o Secretário do Meio Ambiente e Infraestrutura anunciou:

\footnotetext{
O polo criaria um ramo industrial inexistente no estado. Mudaria o panorama da economia gaúcha. A indústria química é uma das mais fortes [...] a estimativa de que a atividade seria capaz de gerar R $\$ 23$ bilhões a mais no Produto Interno Bruto (PIB) estadual ao longo de 20 anos, elevando-o em 4,4\%. (GONZATTO, 02/08/19).
}

Mencionado na mídia regional desde 2014, o Projeto Mina Guaíba conta com apoio contínuo. Em abril de 2017, a Federação de Indústrias do RS organizou o seminário As novas perspectivas para o uso sustentável do carvão, com painel central com o título "A importância do uso sustentável do carvão e a sua vocação carboquímica para soluções regionais em substituição de importações no RS”. A programação incluía palestras pelo presidente da Frente Parlamentar da Mineração na Assembleia Legislativa, além de representantes das empresas ChemVision e COPELMI. Em maio de 2019, a Sociedade de Engenharia do RS organizou o seminário Novos aproveitamentos para o carvão mineral no RS: tecnologias inovadoras, listando os mesmos palestrantes de dois anos antes. Segundo registro pela imprensa (KLEIN, 15/05/19), o vice-prefeito de Charqueadas questionou os ataques "injustos e infundados" por ambientalistas contra a mina, propondo "criação de políticas de proteção econômica do carvão para evitar oscilações injustas e cruéis" dos preços.

\section{A privatização do planejamento metropolitano?}

Ao mesmo tempo em que o EIA estava em elaboração, o governo estadual encaminhou projeto de lei extinguindo - entre outras organizações - a Fundação Estadual de Planejamento Metropolitano (METROPLAN). A extinção da fundação foi aprovada pela Assembleia Legislativa mediante a Lei N. 14.982 de 16/01/2017. A Promotoria de Defesa do Patrimônio Público/RS protocolou ação civil pública contra a extinção da METROPLAN, 
obtendo liminar, em março de 2018, mantendo o planejamento metropolitano no RS no limbo jurídico.

A extinção da METROPLAN pode ser compreendida no quadro de crise fiscal que atinge o RS, desde início de 2015, quando foi superado o limite de endividamento legal. O estado perdeu tanto grau de investimento, como capacidade de pagamento para novos empréstimos e vem parcelando o pagamento dos servidores. Liminar obtida junto ao Supremo Tribunal Federal, em 2017, permitiu a suspensão das parcelas do refinanciamento junto ao governo federal. Segundo análise pela Fundação de Economia e Estatística, o governo gaúcho se financia mediante atrasos com fornecedores e servidores, decorrente de 40 anos de déficits anuais correntes, além do déficit estrutural da previdência estadual (MARQUES JUNIOR, 2015).

As audiências públicas do licenciamento da Mina Guaíba.

A primeira audiência pública foi organizada pela Fundação Estadual de Proteção Ambiental (FEPAM) para o dia 14/03/2019, na cidade de Charqueadas. O evento foi agendado para as $18 \mathrm{~h} 00$ no salão do Clube Tiradentes, na sede do município. Organizações ambientalistas obtiveram, no dia anterior, liminar na Justiça Federal suspendendo a audiência. A FEPAM recorreu e obteve no dia do evento a cassação da liminar. Nota pela imprensa registra (ESSVEIN, 15/03/19) que a audiência comportou mais de 600 pessoas sob escolta da polícia militar, tendo como palestrantes representantes das empresas COPELMI e Tetra Tech. Representantes do assentamento de reforma agrária protestaram contra a perda da terra, moradores expressaram angústia pela dúvida, desde 2014, quanto à remoção forçada de suas residências.

A segunda audiência pública foi organizada pela FEPAM para o dia 27/06/2019, na cidade de Eldorado do Sul. O evento foi marcado para as $18 \mathrm{~h} 00$ no ginásio de uma escola municipal na sede do município. Registro pela imprensa (TRAININI, 28/06/19) da presença de mais de 1.200 pessoas aglomeradas no estádio, com debates e manifestações até a madrugada. Chamou atenção não apenas a presença de grupos organizados com cartazes, faixas e fantasias, tanto a favor, como contra o projeto, mas, o número de crianças e jovens em idade escolar trazidos de ônibus a convite do empreendedor do município de Butiá, trajando camisetas com dizeres favoráveis ao projeto.

Do ponto de vista do órgão ambiental o processo de consulta estava encerrado, quando os Ministérios Público Estadual e Federal decidiram atender às reivindicações e polêmicas expressas através da mídia regional e pronunciamentos em Câmaras Municipais e na Barbarói, Santa Cruz do Sul, Edição Especial n.54, p.<173-19o>, jul./dez. 2019 
Assembleia Legislativa. A Promotoria Estadual do Meio Ambiente organizou a terceira audiência pública para o dia 20/08/2019, na cidade de Porto Alegre. O evento foi marcado para as $18 \mathrm{~h} 00$ no auditório da sede do Ministério Público, que comporta máximo de 500 pessoas. A imprensa (LAITANO, 20/08/19) registra o evento com lotação esgotada, interessados circulando na parte externa do prédio e discussão polêmica no plenário até altas horas da madrugada.

\section{A qualidade do carvão gaúcho e as estatais chinesas.}

A economia gaúcha conta duas experiências com a construção de termelétricas a carvão por estatais chinesas, a privada UTE Pampa Sul e a estatal UTE Candiota III, ambas desabonadoras. A UTE Pampa Sul encontra-se a venda desde 2016, em pleno processo de construção, quando a nova proprietária, a paraestatal francesa ENGIE, maior geradora privada de energia no Brasil, anunciou a intenção de descarbonizar suas operações e priorizar a imagem sustentável.

A experiência no município de Candiota pode ser utilizada como proxy ao debate na RMPA. A polêmica envolvendo o licenciamento da UTE Pampa Sul, em 2009, gerou confronto entre os interesses do então investidor Eike Batista e a oposição pelo então Ministro do Meio Ambiente, Carlos Minc, que chegou a anunciar que a licença somente seria concedida mediante programa de reflorestamento para compensar as emissões de dióxido de carbono (BRASIL, 19/03/09). Por interferência da Presidência da República o ministro teve que recuar em sua posição.

Dado seu peso simbólico e político, o caso da estatal UTE Candiota III foi incluído em estudo coordenado pelo IPEA que concluiu que este tipo de projeto público tem sido "territorialmente cego", "não há coordenação federativa" e a "gestão é reativa" (LOTTA; FAVARETO, 2016):

- Investimento territorialmente cego: o território como mero espaço que recebe projeto pronto, sendo os impactos negativos minimizados mediante ações compensatórias que visam minimizar a oposição e 'destravar' o empreendimento;

- Presença marginal da coordenação federativa: papel protagonista do governo federal em induzir e executar empreendimentos em infraestrutura; entes federativos são pouco envolvidos nos processos decisórios relevantes do planejamento; 
- Coordenação intersetorial a posteriori e reativa: limitada integração entre as políticas públicas no ciclo de formulação e implementação dos projetos de infraestrutura; ação múltipla ocorre após surgimento dos problemas locais.

Adicionalmente, "o país vizinho [Uruguai] alegava que as emissões de gases e cinzas da mina seriam responsáveis pela chuva ácida que incidia na região da fronteira" (ALVES, 2017, p. 18).

Estas parecem dimensões concretas para comparação e análise com o caso aqui proposto, na medida em que o carvão gaúcho, independente da jazida, apresenta baixa qualidade. De acordo com dados publicados pela Empresa de Pesquisa Energética (EPE), o carvão mineral no município de Charqueadas, na RMPA, tem baixo valor calorífico de 2.950 $\mathrm{Kcal} / \mathrm{Kg}$ e alto teor de $54 \%$ de cinzas, "em relação ao padrão norte-americano para especificação de caldeiras a vapor $(6.210 \mathrm{kcal} / \mathrm{kg})$ pode-se dizer que se gasta praticamente o dobro da quantidade de carvão [...] para produzir a mesma quantidade de energia elétrica" (EPE, 2007, p. 119). Estudo pelo IPEA sobre a UTE Candiota III registra que:

O maior problema do projeto foi descoberto na fase de testes da usina, quando se percebeu o efeito abrasivo das cinzas do carvão (de baixa qualidade) sobre o equipamento chinês [...] este imprevisto tem trazido prejuízos à companhia que acionou a empresa chinesa judicialmente (ALVES, 2017, p. 18).

O carvão gaúcho é de baixa qualidade, as indústrias siderúrgicas brasileiras importam mais de 14 milhões de toneladas anuais de carvão metalúrgico.

\section{Discussão}

A implantação do Projeto Mina Guaíba, primeira etapa para instalação de um Polo Carboquímico na RMPA, efetivamente prescinde de mecanismos de participação popular por conjunção de quatro fatores que tornam as atuais audiências públicas inócuas.

\section{Política Estadual de Mineração.}

A atual administração estadual do RS teve seu plano de governo legitimado pelo voto popular nas eleições de outubro de 2018. Além disso, a prioridade para o estímulo à industrialização do carvão mineral no estado obteve legitimidade mediante aprovação pela Assembleia Legislativa da Lei N. 15.047 de 29 de novembro de 2017, que institui o Polo Carboquímico na RMPA. A aliança público-privada entre o Executivo e a mineradora COPELMI está prevista no objetivo Estratégico N. 2 - Aproximar governo e setor privado para priorizar e melhor direcionar recursos e esforços, da Política Estadual de Mineração, que 
declara como objetivo maior o desenvolvimento sustentável do estado. O Projeto Mina Guaíba, portanto, prescinde da aprovação popular.

Como já fora experimentado pela sociedade gaúcha, nos anos 2000, no caso da polemica envolvendo a construção da termelétrica a carvão mineral UTE Candiota III por decisão autocrática do governo federal. Um megaprojeto de infraestrutura que obteve as licenças ambientais, políticas e financeiras necessárias para sua viabilização, prescindindo, porém, da licença social (LOTTA; FAVARETO, 2016). Neste sentido, pode-se inferir que as audiências públicas em curso para o Projeto Mina Guaíba constituem concessão temporária da aliança público-privada no intuito de prover uma licença social mínima, uma fachada de legitimidade, que não coloca em risco a execução do projeto conforme previsto pelo empreendedor.

\section{Greenwashing do PROCARVÃO-RS.}

O Governo do RS adotou para o PROCARVÃO-RS uma estratégia de marketing baseada na associação com conceitos como ‘carvão limpo' ou 'carvão sustentável', conhecida - e condenada - no debate internacional sobre fontes renováveis de energia para a adaptação à mudança climática. Esta estratégia contradiz o conhecimento acadêmico quanto ao caráter poluente do carvão mineral; assim como a política federal de desincentivo para termelétricas a carvão mineral e a Política Gaúcha sobre Mudanças Climáticas.

A aliança pública-privada coordenada entre o governo do RS, prefeituras e câmaras municipais da Região Carbonífera, a mineradora COPELMI, a Federação de Indústrias do RS, a Sociedade de Engenharia do RS e a Sociedade de Engenheiros de Porto Alegre, utiliza de forma recorrente os conceitos de 'carvão limpo' e 'uso sustentável do carvão', buscando reduzir por antecipação críticas e dúvidas quanto às promessas de desenvolvimento sustentável feitas tanto no plano do PROCARVÃO-RS como no EIA/RIMA.

Confunde-se a política pública do PROCARVÃO-RS com o projeto privado da Mina Guaíba. Com base na empiria, pode-se inferir que organizações que adotam uma estratégia de Greenwashing não estão abertas ao diálogo ou ao questionamento, estão decididas quanto ao seu propósito. Pode-se ainda inferir que, no que depender dos empreendedores e da Secretaria Estadual do Meio Ambiente e Infraestrutura, as audiências públicas constituem contratempo pontual no licenciamento. São esferas temporárias de reclamação impostas por força de lei, não representando verdadeira espaço de participação popular que inclua a opção de colocar em risco a execução do projeto. 


\section{Decisão pelo Governo da China.}

Em janeiro de 2013, no auge do inverno, a Região Metropolitana de Pequim passou por um apagão ambiental, conhecido no debate internacional como Airpocalypse, devido ao excesso de poluentes oriundos das termelétricas a carvão mineral. Empresas, órgãos públicos e escolas foram fechados para manter a população em casa, a circulação de veículos foi limitada. O choque junto ao governo central teve como reação, em 2014, a política conhecida pelo título da "Guerra à Poluição" (AGÊNCIA BRASIL, 13/04/14). O governo passou a divulgar, em tempo real, os índices da poluição atmosférica nas 74 áreas metropolitanas do país, nova legislação proibiu a construção de termelétricas a carvão nas regiões metropolitanas e em 12 províncias, termelétricas existentes foram renovadas e utilizam gás natural, servidores públicos foram de casa em casa substituir aquecedores por modelos similares a gás ou energia elétrica.

Segundo estudo por Greenstone; Schwarz (2018), pesquisadores da Universidade de Chicago, a política chinesa de restrição ao uso do carvão mineral está surtindo efeito. Entre 2013 e 2017, os índices de poluição atmosférica nas regiões metropolitanas caíram em média $36 \%$, portanto, acima das metas do governo central. Pesquisadores da Universidade de Hong Kong, porém, enfatizam os altos índices de poluição do ar por combustão de carvão mineral, precificando o custo das externalidades em USD 38 bilhões anuais mediante impactos na saúde pública e redução de safras agrícolas (GU et al., 2018).

Buscando limitar a crise no setor de engenharia de termelétricas, o governo da China fomenta com créditos subsidiados a exportação da experiência em planejamento e a capacidade produtiva instalada (MI et al., 2018). Originalmente conhecida por exportar as emissões de gases de efeito estufa embutidas em seus produtos manufaturados (DAVIS; CALDEIRA, 2010), desde 2014, a China tornou-se o maior financiador e exportador mundial de equipamentos para novas unidades a carvão em países com baixos índices de controle ambiental, com Paquistão, Bangladesh e África do Sul (NASCIMENTO; MAY NETTO, 2019).

Entre 2017/18, a China firmou contratos para financiar USD 36 bilhões em termelétricas a carvão em 23 países, “a China está exportando sua expertise e redundante capacidade de produção de energia de carvão mineral para o mundo [...] tornando-se o último recurso para quem ainda quer investir em carvão mineral em mercados pouco regulados" (SHEARER, BROWN, BUCKLEY, 2019, p. 1, tradução livre). A política PROCARVÃO-RS parece estar pavimento o caminho para que a RMPA integre este esforço da política para preservar empregos no setor do carvão mineral da China.

Barbarói, Santa Cruz do Sul, Edição Especial n.54, p.<173-19o>,jul./dez. 2019 
A política chinesa de exportação de equipamentos industriais de processamento do carvão mineral prescinde da participação popular. Conforme constatado pelo IPEA em análise crítica do uso das audiências populares pelo governo federal, uma vez decidida por uma aliança público-privada a construção de um megaprojeto, não existe questionamento popular que faça reverter a decisão. Como ilustrado pelos casos da usina de Belo Monte ou a Transposição do Rio São Francisco. A empiria reforça que apenas a inviabilidade do financiamento pode impedir a execução de um megaprojeto, como o caso do cancelamento da termelétrica a gás natural liquefeito, em 2017, planejada pela empresa Bolognesi para localização no porto de Rio Grande.

Utilizando conceituação por Lotta; Favareto (2016), o investimento da Mina Guaíba é territorialmente cego, na medida em que foi deliberado, planejado e financiado em uma rede internacional de centros de decisão, situados em cidades da China e dos EUA, para os quais deve fluir o retorno de capital ao longo da vida útil projetada de 24 anos. O investimento contraria ordenamento territorial por políticas públicas, na medida em que prevê remoção de um assentamento de reforma agrária reconhecido como líder na produção de arroz agroecológico. Neste sentido, pode-se inferir que as audiências públicas em curso na RMPA constituem esforço temporário de conferir legitimidade a decisões tomadas desde 2013/14 em cidades que não integram a RMPA, pois localizadas nos EUA e na China.

\section{Audiências públicas sem poder deliberativo.}

A audiência pública constitui, por definição, um espaço de consulta, uma ouvidoria, no qual a organização responsável por um megaprojeto se dispõe a ouvir reclamações e sugestões. Os comentários recebidos dos presentes no evento são registrados, classificados e arquivados. A não ser que demandado por decisão judicial, não existe obrigação pelo organizador de alterar o projeto com base nos comentários recebidos durante a consulta, menos ainda de cancelar o projeto.

Audiências públicas não possuem caráter deliberativo, menos ainda tem poder sobre a execução orçamentária. Elas não impedem a execução do projeto, apenas adicionam condicionantes à listagem de gastos extras pelo investidor. A empiria reforça que mesmo as condicionantes aprovadas pelo órgão ambiental não são cumpridas no país, ou cumpridos apenas parcialmente e de má vontade pelo empreendedor, mesmo quando interpelado judicialmente. No capitalismo brasileiro, o não cumprimento das condicionantes ambientais ou sociais é considerado um delito de cavaleiro que não é punido pelo mercado e não impede, 
por exemplo, a empresa de integrar fóruns empresariais de debate sobre sustentabilidade ou a publicação de relatórios no modelo GRI.

Utilizando o índice de efetividade de mecanismos participativos proposto pela Escada de Arnstein, pode-se inferir que as audiências públicas realizadas, até agosto de 2019, no âmbito do licenciamento da Mina Guaíba estão situadas entre o Nível 4 - Consulta e 5 Pacificação. As pessoas são vistas como abstrações estatísticas e a participação é mensurada pelo número de pessoas presentes, quantidade de folhetos distribuídos ou número de pessoas entrevistadas. As audiências permitem aos cidadãos aconselhar e planejar temporariamente, mas reserva aos gestores o direito de decidir sobre a legitimidade e a viabilidade das sugestões apresentadas pelos cidadãos.

\section{Conclusões}

Entre 2014 e 2018, foi forjada uma aliança entre setores industriais gaúchos e o parque industrial de equipamentos de processamento do carvão mineral na China, buscando reproduzir na Região Metropolitana de Porto Alegre um dos paradigmas da Revolução Industrial: a combustão do carvão mineral, fonte de chuva ácida e de partículas poluentes do ar. Após três décadas de fomento à inovação para qualificação da democracia gaúcha, a sociedade civil aparenta estar desgastada, sem forças para oposição ao Projeto Mina Guaíba e o Polo Carboquímico. Centra sua restrita capacidade de articulação no debate sobre a distribuição dos restos orçamentários da Consulta Popular, segundo critérios da Escada de Arnstein, antes cooptação que participação popular.

O Projeto Mina Guaíba, megaprojeto de mineração de carvão mineral em processo de licenciamento no Rio Grande do Sul, está sendo apresentado à opinião pública pelo empreendedor e pelo Governo Estadual como um empreendimento 'sustentável', de processamento do 'carvão limpo'. As empresas estrangeiras citadas como futuros sócios do empreendimento tem suas sedes situadas em regiões que estão cortando o volume de mineração de carvão, caso da Pennsylvania/EUA, ou que definiram data limite para finalizar compra de energia gerada com carvão mineral, caso da Califórnia/EUA, ou em país que proibiu novas termelétricas a carvão em regiões metropolitanas, caso da China.

Argumentamos que a combinação de quatro fatores, i) Política estadual de mineração; ii) Greenwashing do PROCARVÃO-RS; iii) Decisão pelo Governo da China e iv) Audiências públicas sem poder deliberativo, contribuem para a interpretação nesse ensaio de que apesar da polemica nos meios de comunicação quanto ao projeto, nenhuma das três audiências públicas tenha: i) alterado de forma significativa o projeto, ou mesmo ii) impedido a sua Barbarói, Santa Cruz do Sul, Edição Especial n.54, p.<173-19o>, jul./dez. 2019 
execução. As audiências públicas representam espaço de reclamação e registro da insatisfação, mas são inócuas quanto aos rumos do investimento.

Audiências públicas tem entre seus objetivos declarados contribuir para a legitimidade do megaprojeto, seja público ou privado. Argumentamos que as três audiências públicas realizadas no licenciamento do Projeto Mina Guaíba, em 2019, atendem aos critérios formais do órgão ambiental e do Ministério Público para arquivo e registro público. Não logrando, porém, construir uma licença social favorável ao projeto na RMPA tendo em vista a contínua polêmica reproduzida pela mídia regional.

As três audiências públicas realizadas não alteraram a formulação da Política Gaúcha de Mineração. Possivelmente apenas reforçaram a Estratégia 4 - Promover a imagem e o papel transformador da mineração, que prega o Estado como defensor do setor da mineração mediante uma ativa estratégia de marketing. As audiências também não alteraram na formulação do PROCARVÃO-RS, ou modificaram a legislação que autoriza a instalação de um Polo Carboquímico na RMPA.

\title{
WHEN CITIZEN PARTICIPATION IS INNOCUOUS: THE GREENWASHING OF COAL IN THE METROPOLITAN AREA OF PORTO ALEGRE/BRAZIL
}

\begin{abstract}
This essay proposes a critical analysis of the participatory mechanisms used in the licensing process of the Project Mina Guaíba in the metropolitan area of Porto Alegre, Rio Grande do Sul state. Covering 4,380 hectares, it will become the largest open-pit mine in the country, aiming to supply a thermoelectric power plant, gasification plant and fertilizer industries built by Chinese state-owned companies. It discusses the hypothesis that the decision to build the pole was encouraged by the Chinese government, which, since the 2013 air pollution crisis, has financed the export of idle capacity for planning and building industrial facilities. In a receptive way, the state government created, in 2017, the PROCARVÃO-RS program seeking to attract Chinese expertise and capital. Using the Ladder of Citizen Participation by Arnstein as reference, it concludes that public hearings held in the metropolitan region are innocuous within the objectives of the state's Climate Change Policy, as they do not alter the project, restricting itself to adding compensatory measures.
\end{abstract}

Key words: Coal. Air pollution. Guaíba Mine. 


\section{REFERÊNCIAS}

AGÊNCIA BRASIL. Guerra à poluição na China será 'batalha difícil' diz primeiro ministro. 13/04/2014. Disponível em: 〈https://agenciabrasil.ebc.com.br〉. Acesso em: 20/09/19.

ALVES, L. Condicionantes institucionais à execução do investimento em infraestrutura no Brasil: o caso da UTE Candiota III. Relatório de pesquisa. Rio de Janeiro: IPEA, 2017. ARNSTEIN, S. A ladder of citizen participation. Journal of the American Planning Association, v. 35, n. 4, p. 216-224, 1969.

AVRITZER, L.; NAVARRO, Z. (Orgs.) A inovação democrática no Brasil: o orçamento participativo. São Paulo: Cortez, 2003.

BRASIL. MINISTÉRIO DO MEIO AMBIENTE. Termelétricas terão que compensar emissões de CO2. 19/03/2009, Brasília. Disponível em: <https://mma.gov.br/informamma〉. Acesso em: 18/08/19.

COPELMI; ABG; TETRA TECH (2018). Relatório de impacto ambiental: mina de carvão Guaíba. Porto Alegre/São Paulo.

DAVIS, S.; CALDEIRA, K. Consumption- based accounting of CO2 emissions. PNAS, v. 107, n. 12, p. 5687-5692, mar. 2010.

EMPRESA PESQUISA ENERGÉTICA (EPE). Plano nacional de energia 2030. Ciclo 2006/07. V. 6 Geração termelétrica: carvão mineral. Rio de Janeiro, 2007.

ESSVEIN, M. Charqueadas: realizada audiência pública para apresentação do EIA da Mina Guaíba. 15/03/19. Disponível em: 〈https://www.portaldenoticias.com.br〉. Acesso em: 02/09/19.

FARIA, C. Fóruns participativos, controle democrático e a qualidade da democracia no RS: a experiência do governo Olívio Dutra (1999-2002). Revista Opinião Pública, v. 12, n. 2, p. 378-406, 2006.

FONSECA, I. Participação como método de governo: experiências transcalares no Rio Grande do Sul/Brasil e na Toscana/Itália. Brasília: IPEA, 2019.

FONSECA, I. (Coord.) Fatores críticos das audiências públicas do governo federal. Nota Técnica N. 4. Brasília: IPEA, 2013.

FONSECA, I. (Coord.) Potencial de efetividade das audiências públicas do governo federal. Relatório de Pesquisa. Brasília: IPEA, 2013(a).

FONSECA, I.; ALENCAR, J. (Coords.) Audiências públicas no âmbito do governo federal: análise preliminar e bases para avaliação. Relatório de pesquisa. Brasília: IPEA, 2012.

GONZATTO, M. Plano de polo carboquímico amplia polêmica sobre mina no RS. 02/08/19. Disponível em: 〈https:gauchazh.clickrbs.com.br〉. Acesso em: 07/08/19. 
GREENSTONE, M.; SCHWARZ, P. Is China winning the war on pollution? Relatório de pesquisa. Chicago: University of Chicago. mar. 2018.

GU, Y.; WONG, T.; LAW, C.; DONG, G.; HO, K.; YANG, Y.; YIM, S. Impacts of sectoral emissions in China and the implications: air quality, public health, crop production, and economic costs. Environmental Research Letters, v. 13, n. 8, 2018.

INSTITUTO DE DEFESA DO CONSUMIDOR (IDEC). Mentira verde: a prática de greenwashing. Relatório de pesquisa. São Paulo, 2019.

KLEIN, J. Copelmi avalia ampliar projeto carboquímico. Jornal do Comércio. Porto Alegre, 15/05/19. Caderno Geral, p. 14.

LAITANO, V. Audiência em Porto Alegre confronta posições sobre implantação de Mina Guaíba. 20/08/19. Disponível em: <https:///www.jornaldocomercio.com>. Acesso em: 02/09/19.

LOTTA, G.; FAVARETO, A. Os arranjos institucionais dos investimentos em infraestrutura no Brasil: uma análise sobre seis grandes projetos do PAC. Texto para discussão N. 2253, Rio de Janeiro: IPEA, 2016.

MARQUES JUNIOR, L. A crise financeira do RS e seus componentes. Carta de Conjuntura FEE. Porto Alegre, v. 24, n. 10, p. 1, 2015.

MI, Z.; MENG, J.; GREEN, F.; COFFMAN, D.; GUAN, D. China's 'exported carbon' peak: patterns, drivers, and implications. Geophysical Research Letters, v. 45, n. 9, p. 4309-4318, 2018.

NASCIMENTO, L.; MAY NETTO, M. One Belt, One Road: a iniciativa chinesa de infraestrutura e sua repercussão no BRICS. Brazilian Journal of International Relations, v. 8, n. 1, p. 117-141, 2019.

PIRES, R. (Org.). Efetividade das instituições participativas no Brasil: estratégias de avaliação. Diálogos do desenvolvimento 7. Brasília: IPEA, 2011.

RIO GRANDE DO SUL. ESCRITÓRIO DE DESENVOLVIMENTO DE PROJETOS (EDP). Secretaria do Meio Ambiente e Infraestrutura 2019/2022. Slides de apresentação. Plano Estratégico GOV RS Novas Façanhas. Porto Alegre, 2019.

RIO GRANDE DO SUL. SECRETARIA DE MINAS E ENERGIA. Mineração no Rio Grande do Sul: diagnóstico setorial e visão de futuro. V. 1 Sumário Executivo. Porto Alegre, nov. 2018.

SANTOS, B. (Org.) Democratizar a democracia: os caminhos da democracia participativa. Rio de Janeiro: Civilização Brasileira, 2002.

SHEARER, C.; BROWN, M.; BUCKLEY, T. China at a crossroads: continued support for coal power erodes country's clean energy leadership. Cleveland: IEEFA, jan. 2019. 
SILVA, S. Democracia, políticas públicas e instituições de deliberação participativa: visões sobre a experiência brasileira. Texto para Discussão N. 2358. Brasília: IPEA, 2018.

STRECK, D. O Fórum Social Mundial e a agenda de educação popular. Revista Brasileira de Educação, n. 26, p. 58-181, mai./ago.2004.

TAVARES, P. Os modelos de participação popular no RS: as experiências do orçamento participativo e do processo de participação popular. Dissertação (Mestrado) Ciências Sociais. Pontifícia Universidade Católica, Porto Alegre, 2006.

TIRELLI, C.; AGOSTINI, C. Sociedade civil, instâncias participativas e desenvolvimento: o caso dos conselhos regionais de desenvolvimento no estado do RS. Revista REDES, v. 20, n. 3, p. 284-302, set./dez. 2015.

TRAININI, C. Audiência pública debate instalação da Mina Guaíba. 28/06/19. Disponível em: <https://www.portaldenoticias.com.br>. Acesso em: 02/09/19.

\section{Sobre o autor:}

Markus Erwin Brose pertence ao Departamento de Ciências Humanas, Universidade de Santa Cruz do Sul. Eletrônico: markus@unisc.br 